\title{
Giant dumbbell-shaped schwannoma but not transforaminal: transdiaphragmatic
}

\author{
Ferhat Cuce, ${ }_{1}^{1}$ Kemal Kara, ${ }^{2}$ Muntecep Asker, ${ }^{3}$ Guner Sonmez ${ }^{2}$
}

${ }^{1}$ Department of Radiology, Van Military Hospital, Van, Turkey 2Department of Radiology, GATA Haydarpasa Training Hospital, Istanbul, Turkey ${ }^{3}$ Department of Cardiology, Van Training and Research Hospital, Van, Turkey

\section{Correspondence to} Dr Ferhat Cuce,

ferhatcuce@hotmail.com

Accepted 3 May 2014

\section{SUMMARY}

A 31-year-old man reported a 3-month history of right upper abdominal pain and effort dyspnoea. The laboratory data demonstrated no abnormality. On abdominal ultrasound, a gross solid lesion with smooth borders was seen behind the liver. CT scan revealed a huge tumour, $23 \times 17 \times 15 \mathrm{~cm}$ in size, it was in the right posterior mediastinum and extended to the right retroperitoneum. In sagittal plane $\mathrm{CT}$ images, the lesion was like a dumbbell shape. CT-guided biopsy revealed a spindle cell tumour.

\section{BACKGROUND}

First, schwannoma should be kept in mind for the differential diagnosis of a giant thoracoabdominal solid lesion. Second, the dumbbell-shaped tumour is a non-specific term for any of a number of usually benign tumours. The nerve sheath tumour may assume the shape of a dumbbell as a classic when the tumour extends outward the spinal canal through the vertebral foramen. This finding may contribute to the diagnosis. But the dumbbell shape of the nerve sheath tumours could occur anywhere except vertebral foramen as seen in our patient.

\section{CASE PRESENTATION}

A 31-year-old man reported of right upper abdominal pain and effort dyspnoea for 3 months. $\mathrm{He}$ had a good general condition and had no 'B symptoms'. On physical examination, the patient had tenderness during palpation of the right upper quadrant of the abdomen and there were crackles at the right base of the chest on auscultation.

The patient had no significant medical, social or family history.

\section{INVESTIGATIONS}

No significant abnormalities were found on standard blood tests.

His chest X-ray revealed homogen opacity at the inferior and middle zone of the right haemithorax.

On abdominal ultrasound, a gross solid lesion with smooth borders was detected behind the liver.

The thoracoabdominal multidetector CT (MDCT) with contrast media was performed. MDCT revealed a huge tumour, $23 \times 17 \times 15 \mathrm{~cm}$ in size, in the right posterior mediastinum extended to the right retroperitoneum. The lesion was solid, encapsulated and had diffuse mild contrast enhancement. The tumour did not contain areas of fat and calcification density (figure 1A, B).

In sagittal plane MDCT images, the lesion was like a dumbbell shape (figure 2).
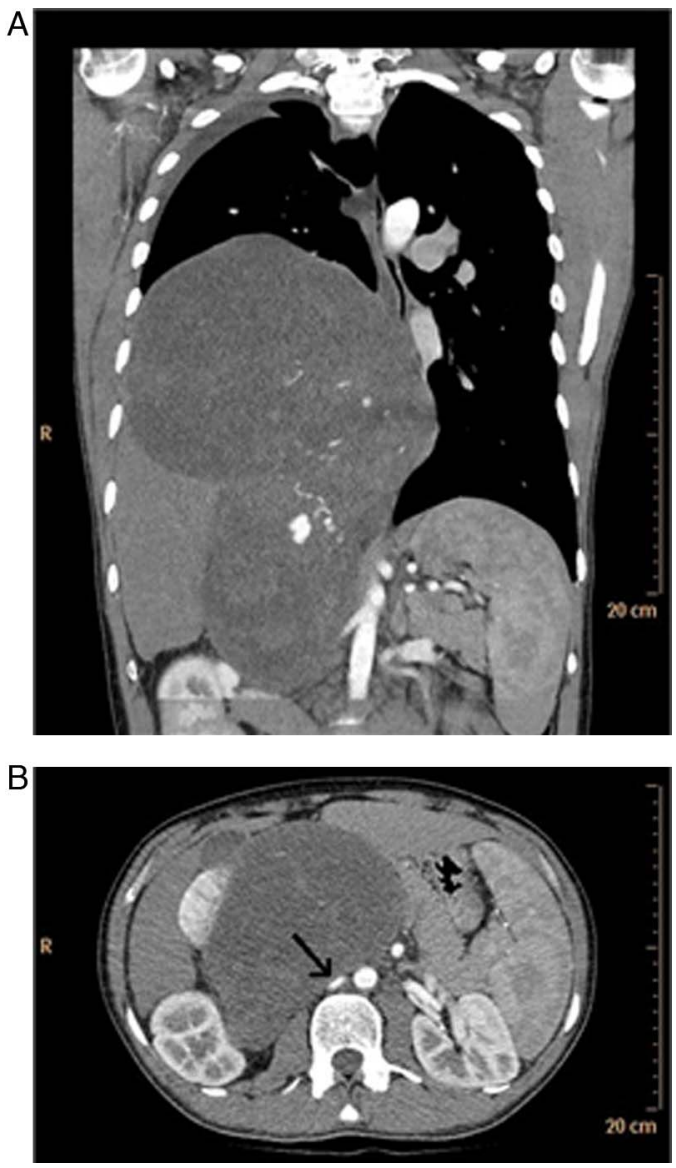

Figure 1 (A) Coronal CT scan showing the right posterior mediastinal tumour that extends towards the right retroperitoneum. (B) Axial CT scan showing retroperitoneal tumour behind the liver compresses the inferior vena cava (black arrow).

\section{DIFFERENTIAL DIAGNOSIS}

A 31-year-old man presented with right upper abdominal pain and effort dyspnoea for 3 months without B symptoms. On physical examination, the patient had tenderness on the right upper quadrant of the abdomen and there were crackles at the right base of the chest on auscultation. He might have a renal stone or gallstone disease, liver parenchymal disease or lower lobe infection of the right lung. His chest X-ray revealed a homogen opacity at the inferior and middle zone of the right haemithorax and on abdominal ultrasound, a gross solid lesion was detected behind the liver. Radiological examinations revealed that the symptoms were due to the giant solid thoracoabdominal mass.

The giant solid thoracoabdominal tumour was considered as a sarcomatous tumour or a nerve sheath tumour in the differential diagnosis. 


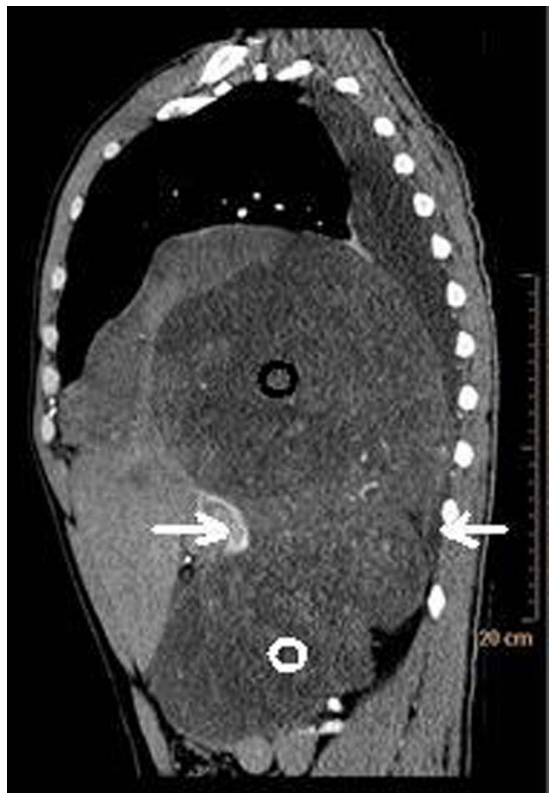

Figure 2 Sagittal CT scan showing a giant thoracoabdominal dumbbell-shaped tumour. The intrathoracic (black rim) and retroperitoneal (white rim) parts of the tumour are connected by a relatively narrow segment (arrow) passing through the diaphragma.

\section{TREATMENT}

The MDCT images indicated a giant sarcomatous tumour or nerve sheath tumour in the differential diagnosis. CT-guided biopsy revealed a spindle cell tumor. Surgical resection was recommended. The tumour was completely resected en bloc with a portion of adhered left lower lobe and the right hemidiaphragm. The frozen section of the pleural and the diaphragmatic margin was found to contain no tumour. The diaphragmatic defect was repaired with a graft. The final pathology demonstrated the mass consistent with schwannoma characterised by a proliferation of spindle cells.

\section{OUTCOME AND FOLLOW-UP}

The postoperative period was uneventful and the patient was discharged home without complication. At 12-month follow-up, the patient was free from recurrence.

\section{DISCUSSION}

The term of dumbbell is used for schwannoma when the intraspinal schwannoma extends through the vertebral foramen into the posterior mediastinum or retroperitoneum. ${ }^{12}$ Although dumbbell shape of tumour is not specific for nerve sheath tumour, it may give clues for primary diagnosis. In our patient, the sagittal view of the schwannoma which passed through the diaphragma evoked the dumbbell shape similar to that known in vertebral foramen as a classic.

Giant schwannoma is rarely located in the retroperitoneum and pelvis. ${ }^{3}$ It is a slow growing tumour. As the symptoms and clinical signs are due to the compression of adjacent organs by the tumour, schwannomas could reach upto very big sizes. The differential diagnosis of a giant thoracoabdominal solid lesion includes tumours of the oesophagus, lymphoma, sarcomas besides the neurogenic tumours such as schwannoma and neurofibroma. ${ }^{4}$

Schwannoma typically appears as a solitary, sharply demarcated and well-capsulated round mass with smooth borders on CT images. ${ }^{6}$ The lesion has moderate contrast enhancement and could show punctate calcifications. MRI usually demonstrates low intensity in T1-weighted images and high intensity in T2-weighted images in the tumour. The characteristics of the lesion on CT were consistent for schwannoma in our case.

\section{Learning points}

- Schwannoma should be kept in mind for the differential diagnosis of a giant solid thoracoabdominal lesion.

- The dumbbell-shaped tumour is a non-specific term for any of a number of usually benign tumours.

- The nerve sheath tumour may assume the shape of a dumbbell as a classic when the tumour extends outward the spinal canal through the vertebral foramen. This finding may contribute to the diagnosis. But dumbbell shape of the nerve sheath tumours could occur anywhere except in the vertebral foramen.

Competing interests None.

Patient consent Obtained.

Provenance and peer review Not commissioned; externally peer reviewed.

\section{REFERENCES}

1 Quarteya B, Lenertb J, Debc SJ, et al. Giant posterior mediastinal ancient schwannoma requiring thoracoabdominal resection: a case report and literature review. World J Oncol 2011;2:191-4.

2 Bhatia S, Khosla A, Dhir R, et al. Giant lumbosacral nerve sheath tumors. Surg Neurol 1992;37:118-22.

3 Isobe K, Shimizu T, Akahane T, et al. Imaging of ancient schwannoma. AJR Am J Roentgenol 2004;183:331-6.

4 Alavi A, Asadi Gharabaghi M. Unicentric Castleman's disease: an uncommon cause of posterior mediastinal mass. BMJ Case Rep 2013;2013:pii: bcr2012008522.

5 Taki K, Watanabe M, Iwagami S, et al. Giant liposarcoma of the posterior mediastinum and retroperitoneum. BMJ Case Rep 2011;2011:pii: bcr0620114341.

6 Incedayi M, Sivrioglu AK, Ozyurek S, et al. Retroperitoneal ancient schwannoma: multidetector CT findings. BMJ Case Rep 2013;2013:pii: bcr2012008083. 
Copyright 2014 BMJ Publishing Group. All rights reserved. For permission to reuse any of this content visit http://group.bmj.com/group/rights-licensing/permissions.

BMJ Case Report Fellows may re-use this article for personal use and teaching without any further permission.

Become a Fellow of BMJ Case Reports today and you can:

- Submit as many cases as you like

- Enjoy fast sympathetic peer review and rapid publication of accepted articles

- Access all the published articles

- Re-use any of the published material for personal use and teaching without further permission

For information on Institutional Fellowships contact consortiasales@bmjgroup.com

Visit casereports.bmj.com for more articles like this and to become a Fellow 